\title{
VORSITZWECHSEL IN DER VÖB-KOMMISSION DER LANDESBIBLIOTHEKEN
}

\section{von Anita Eichinger}

Harald Weigel führte den Vorsitz der Kommission der Landesbibliotheken 2005 und von 2013 bis 2018. Er hat sich als Leiter der Vorarlberger Landesbibliothek und natürlich als Kommissionsvorsitzender immer für Zusammenhalt und Zusammenarbeit der Landesbibliotheken eingesetzt. Seinem unermüdlichen Engagement für länderübergreifenden Austausch ist es zu verdanken, dass auch Bibliothekarlnnen aus Nachbarländern in der Kommission und bei deren Tagungen vertreten sind. Nun hat er aufgrund seiner bevorstehenden Pensionierung den Vorsitz zurückgelegt. Mit großem Dank und großer Anerkennung für seine Leistungen wurde er in Salzburg verabschiedet. Als neue Vorsitzende wurde Anita Eichinger, Wienbibliothek, einstimmig von den Mitgliedern gewählt.

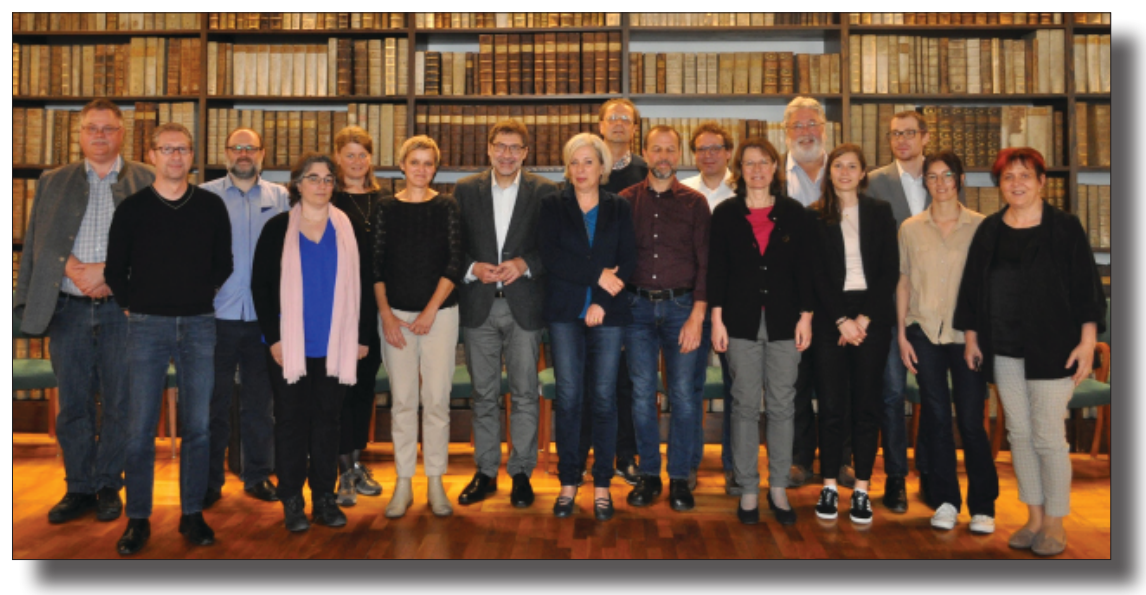

Das Bild zeigt Kommissionsmitglieder und Vortragende am zweiten Tag der Frühjahrstagung der Kommission für Landesbibliotheken, die von 17.18. Mai 2018 an der Universitätsbibliothek Salzburg stattgefunden hat. Hans-Joachim Alscher, Markus Kostajnsek, Maximilian Losinschek, Christine Kinzner, Katharina Kocher-Lichem, Anita Eichinger, Harald Weigel, Sylvia Mattl-Wurm, Jakob Perschy, Gregor Neuböck, Johannes Andresen, Barbara 
Koller-Brettenthaler, Klaus Kempf, Elisa Gorgaini, Christoph Capellaro, Linda Ohrtmann, Ursula Schachl-Raber [v.I.n.r.]. Es fehlen die Vortragenden des Vortages Harald Eberle und Martin Gasteiner. Schwerpunktthemen waren Digitalisierung, Repositorien, Elektronische Pflichtablieferungen (siehe https://www.univie.ac.at/voeb/kommissionen/landesbibliotheken/).

\author{
Dr. ${ }^{\text {in }}$ Anita Eichinger \\ Wienbibliothek im Rathaus \\ E-Mail: anita.eichinger@wien.gv.at
}

DOI: https://doi.org/10.31263/voebm.v71i3-4.2165

(C) Anita Eichinger

Dieses Werk ist lizenziert unter einer

Creative-Commons-Lizenz Namensnennung 4.0 International 